\title{
Editorial
}

\section{Hacia el control de las enfermedades respiratorias}

\author{
Towards respiratory disease control
}

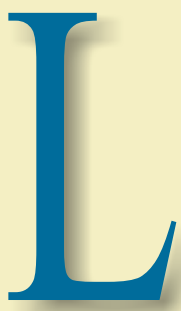

a educación médica es un medio de comunicación, que cumple la finalidad de generar conocimiento, es así, que la revista médica "Diagnóstico" recurre a médicos especialistas que mediante sus publicaciones puedan alcanzar conocimiento a médicos generales de enfermedades prevalentes y con ello, contribuir a que el médico general tenga herramientas actualizadas para que puedan enfrentarse a problemas de salud de la población y logren brindar una atención médica oportuna y de calidad, así como saber prevenir, detectar, manejar y derivar patología específica a los médicos especialistas.

En esta oportunidad, teniendo en cuenta que las enfermedades respiratorias son responsables en un tercio aproximadamente de la consulta médica en general, se ha considerado realizar una revisión sistemática de algunas patologías respiratorias prevalente como las bronquiectasias, o aquellas que presentan incremento de mortalidad en menores de 5 y mayores de 60 años como las neumonías, u otras más frecuente de lo que uno sospecha como el síndrome de apnea del sueño, o las que se encuentran en la actualidad en incremento como es la enfermedad pulmonar intersticial difusa, y por último aquella neoplasia que es reportada como una de las de más alta mortalidad como el Cáncer de pulmón.

En el presente simposio, se revisan estas patologías respiratorias, desde sus definiciones, aspectos fisiopatológicos, sus factores de riesgo, formas clínicas de presentación, metodología de

Recibido: 18.11.2019 Aceptado: 09.12.2019 diagnóstico, diagnósticos diferenciales, conductas terapéuticas, actividades preventivas y recuperativas. Información que se pone a disposición de médicos generales, con la finalidad de mejorar sus competencias, contribuyendo con ello a lograr una atención médica integral de nuestra población, como que también, frente a sospechas de enfermedades respiratorias, las derivaciones tempranas a los especialistas.

Es muy probable, que el presente simposio, no logre cumplir las expectativas de muchos colegas, en virtud que no se estén abordando otras patologías frecuentes como son la infecciones respiratorias agudas, el asma, la enfermedad pulmonar obstructiva crónica, la tuberculosis o el enfoque de la tromboembolia pulmonar, o la insuficiencia respiratoria aguda, o crónica, o el síndrome de distres respiratorio del adulto (SDRA) entre otras patologías respiratorias de importancia clínica, que consideramos deben ser abordadas con prontitud, y así empezar a satisfacer las expectativas de los médicos generales.

Por último, considero que el esfuerzo realizado es un primer intento de reducir las brechas de conocimiento y alertar la existencia de patología respiratoria, muchas veces insospechada, condicionando enfoques inadecuados de algunas enfermedades respiratorias; que, con sucesivas publicaciones, se irán aclarando y reduciendo las brechas de conocimiento; logrando que los médicos generales participen en la detección y control de enfermedades respiratorias en el primer nivel de atención, donde no siempre contaremos con especialistas.

\section{Dr. Carlos Alberto Saavedra-Leveau}

Médico Neumólogo. Magister en Salud Ocupacional y Ambiental.

Doctor en Medicina. Profesor Principal de la Facultad de Medicin de la Universidad Nacional Mayor de San Marcos (UNMSM).

Citar como: Saavedra-Leveau CA. Hacia el control de enfermedades respiratorias. Diagnóstico (Lima). 2019;58(4):171.

DOI:https://doi.org/10.33734/diagnostico.v58i4.171

Correspondencia: Carlos Alberto Saavedra-Leveau Correo electrónico: saavedraleveau@yahoo.com 